\title{
Causes of Neurodegeneration in Diabetes: Possible Culprits and Therapeutic Targets
}

Uthra Rajamani*

University of California Davis Medical Center, 4635 2nd Avenue, Research I Building, Sacramento, CA, USA

"Corresponding author: Uthra Rajamani, University of California Davis Medical Center, 4635 2nd Avenue, Research I Building, Sacramento, CA , 95817, USA, Tel: 916 734 1316; Fax: 916734 6593; E-mail: rautharin@gmail.com

Received date: May 25, 2014, Accepted date: June 02, 2014, Published date: June 16, 2014

Copyright: ( 2014 Rajamani U. This is an open-access article distributed under the terms of the Creative Commons Attribution License, which permits unrestricted use, distribution, and reproduction in any medium, provided the original author and source are credited

\begin{abstract}
Diabetes, a global epidemic, has been shown to be linked to incidence of neurodegenerative disorders. Hyperglycemia is linked to cognitive decline, Alzheimer's disease, dementia and neurodegeneration in general. The mechanisms of diabetes/hyperglycemia-mediated neurodegeneration are largely unknown. This review sheds light on mechanisms that could possibly lead to hyperglycemia-mediated neurodenegeration namely apoptosis, oxidative stress, AGE, etc. Additionally relevant therapeutic strategies are also discussed.
\end{abstract}

Keywords: Hyperglycemia; Neurodegeneration; Aging

\section{Abbreviation: \\ IGT: Impaired Glucose Tolerance; AD: Alzheimer's Disease; GABA- $\gamma$-aminobutyric acid; STZ: Streptozotocin; AGE: Advanced Glycation End product; MMP: Matrix Metalloproteinase; PKC: Protein Kinase C; ROS: Reactive Oxygen species; DAG: Diacyl glycerol \\ Causes of Neurodegeneration in Diabetes - Possible Culprits and Therapeutic Targets}

Diabetes mellitus is fast reaching epidemic proportions globally. About 347 million individuals were affected globally in 2011 [1] further projected to increase to 552 million by 2030 [2]. Moreover impaired glucose tolerance (IGT), a possible condition leading to diabetes is also projected to be up at $7.1 \%$ in 2030 [3]. While the numbers are only increasing with time, several attempts are being made to understand the nature and implications of this disease.

It has been well established that patients with diabetes are at a threefold risk of developing cardiovascular diseases [4]. Interestingly as early as 1976, diabetes was considered to be a kind of "accelerated aging" since it increases an individual's susceptibility to degenerative diseases such as kidney disease, hypertension, coronary artery disease, stroke, atherosclerosis and recently accelerated brain aging [5]. Although diabetes may be associated with increased risk of dementia and brain damage, the mechanisms underlying it is still unclear. If as estimated, prevalence of diabetes in adults increases, thus increasing the risk of dementia, serious implications to public health is almost inevitable.

Neurodegenerative disorders, as the name suggests, is a progressive impairment of any brain function which, like diabetes, predominantly affects the adult population worsening with increasing age. It could either be caused due to impairment of specific neurons or a general neuronal impairment. As a result, some highly specific neuronal functions such as vision, hearing or general brain/neuronal function as observed in dementia are affected. Several neurodegenerative disorders are known to be associated with age-related symptoms such as diabetes, obesity, metabolic syndrome, etc. [6]. There is evidence that neurodegenerative disorders are more prevalent in diabetes compared to incidence in general population. Clinical studies suggest impairment in neuropsychological functioning in diabetic patients [7]. More studies show that diabetics have a higher prevalence of global cognitive impairment [8] and greater cognitive decline [9] compared to normoglycemic individuals. It has also been shown that diabetes is a risk factor for Alzheimer's disease (AD) [10-13]. Furthermore, there were deficits in hippocampal-based memory performance and cognition alongside diabetes-mediated reduction in brain volumes of diabetic individuals [14]. Taking all this into consideration the aim of this review is to discuss the possible mechanisms that link diabetes and neurodegenerative disorders; and to analyze hyperglycemia-mediated apoptosis as a possible causal event in neurodegeneration in diabetics.

\section{Brain Energy Metabolism}

Glucose is the most preferred energy substrate for brain and it is almost entirely oxidized to $\mathrm{CO}_{2}$ and $\mathrm{H}_{2} \mathrm{O}$ under normal conditions [15]. Although brain represents only $2 \%$ of the body weight, it requires about $15 \%$ of the cardiac output, $20 \%$ of total oxygen consumption and $25 \%$ of total body glucose for its functioning [16]. Oxygen consumption and $\mathrm{CO}_{2}$ production in brain is almost identical thus indicating that carbohydrates are its substrates for oxidative metabolism [17]. Glucose apart from being oxidized also enters other metabolic fates such as being incorporated into lipids, proteins and also being utilized as a precursor for certain neurotransmitters such as $\gamma$-aminobutyric acid (GABA), glutamate or acetylcholine $[17,18]$. While glucose is majorly preferred by the brain, under particular conditions of starvation, exercise, diabetes, etc. plasma ketone bodies such as acetoacetate and D-3-hydroxy butyrate are utilized as metabolic substrates [19]. While speaking of glucose as the primary substrate in brain, the major question that arises is what are the effects of hyperglycemia such as in a pre-diabetic/hyperglycemic setting?

It is unclear as to whether glucose uptake is affected in brain in diabetes. Some studies show that there is a comprised blood brain barrier with increased permeability in diabetes [20,21]. Astrocyte gap junction integrity is also reduced in STZ-induced diabetic animals 
Page 2 of 6

[22]. Seaquist et al. however showed that glucose uptake into the brain is independent of plasma insulin levels [23] indicating that insulin resistance might possibly not impact glucose uptake in brain.

\section{Diabetes and Neurodegeneration}

Although there is not much direct evidence showing a link between diabetes and neurodegeneration, several studies have shown a correlation between Type 2 diabetes and brain atrophy and decreased neuronal integrity. There is significantly greater brain atrophy in diabetic patients compared to non-diabetic matched controls [24]. There is also evidence that patients with type 2 Diabetes have a significantly reduced total brain volume and an increased peripheral cerebrospinal fluid volume pointing towards a possible chronic cerebral atrophy [25]. In streptozotocin (STZ) induced diabetic rat models, encephalopathy with neuronal degeneration and inflammation and impairment in gap junction communication has been observed [26].

Interestingly, neurodegenerative diseases have also been shown to affect glucose metabolism in brain. Alzheimer's disease (AD) affected brain exhibits lower metabolic rates of glucose and abnormalities in insulin sensitivity in brain which leads to a hyperglycemic environment which possibly leads to neuronal death [27-29]. Methyl glyoxal (Advanced Glycation End product - AGE) may be a promoter of neuronal death via AGE formation that plays a role in insulin resistance thereby impacting brain glucose metabolism [30]. Insulin resistance decreases glucose metabolism which in turn hyperphosphorylates tau protein causing neurofibrillary tangles [31]. A transgenic mouse model of $\mathrm{AD}$, superimposed with Type 2 diabetes also showed an increased tau protein phosphorylation [32].

Studies have also demonstrated white matter lesions and cerebral atrophy with diabetes $[33,34]$. Increased glycation observed in diabetic patients as well as glycated proteins in AD plaques and neurofibrillary tangles makes it plausible that diabetic patients have increased risk of developing $\mathrm{AD}$-associated brain lesions [5]. Postmortem studies on 216 diabetic patients showed that patients with ApoE- $\varepsilon 4$ allele, which is a genetic risk factor for $\mathrm{AD}$, showed increased hippocampal neuritic plaques, neurofibrillary tangles in cortex and hippocampus as well as a higher risk of cerebral amyloid angiopathy [11]. Another postmortem study with about a 1000 diabetic patients showed that diabetes leads to greater cortical atrophy [34]. Kamada et al. have proposed a hyperglycemic model whereby high glucose levels increases oxidative stress and matrix metalloproteinase-9 (MMP-9) activity which results in blood brain barrier dysfunction after ischemia-reperfusion injury. This data suggests that under hyperglycemic conditions when blood brain barrier is compromised, it could cause inflammatory cells and fluid to penetrate brain leading to edema and cell death [35].

Several studies have also shown impaired neuropsychological functioning in diabetic patients [36]. Simultaneously, this is compounded by genetic factors that impact on the incidence of neurocognitive disorder. Family history of diabetes appears to increase the risk of coronary heart disease (CHD) [37]. Furthermore genetic predisposition to T2DM also has been shown to accelerate atherosclerosis [38]. Interestingly, even in the absence of pre-diabetes or diabetes, subjects who have a family history of diabetes are at a higher risk of cardiovascular diseases (Reviewed in [39]). However, if a family history of diabetes predisposes an individual to neurodegeneration needs to be explored. Several groups have shown that diabetics who are carriers of apolipoprotein E $\varepsilon 4$ allele are more susceptible to cognitive impairment compared to individuals without either diabetes or the allele or both [40-42]. These studies have clearly demonstrated the link between neurodegeneration and diabetes. Possible mechanisms that could bring about neurodegeneration in diabetes will be discussed henceforth.

\section{Neurodegeneration and Apoptosis}

In chronic neurodegenerative diseases, apoptosis is the predominant form of cell death [43-45] and in turn impaired neuronal function. There is evidence suggesting that caspases are activated in $\mathrm{AD}$, Parkinson's disease, and dementia associated with human immunodeficiency virus infection [46-48]. The cause of the selective death of motor neurons in $\mathrm{AD}$, for the most part, not understood. But it can be said with some confidence that apoptosis/activation of apoptotic signaling cascade in specific neurons play a major role in neurodegeneration. As mentioned earlier tau protein hyperphosphorylation results in formation of tangles and eventually neuronal cell death [31]. In general, several works have indicated tau protein hyperphosphorylation as a salient feature in both type 1 and type 2 diabetic models [49]. Hence elucidating the underlying mechanisms of apoptosis in neurodegenerative diseases would provide very useful insights on the disease progression and possible therapeutic targets.

There have been convincing proof that hyperglycemia mediates apoptosis. Also apoptosis of selective neurons is a key event in neurodegenerative disorders. Hence it is important to know if hyperglycemia-mediated apoptosis could be a contributing factor in neurodegeneration of diabetic/pre-diabetic individuals (Figure 1).

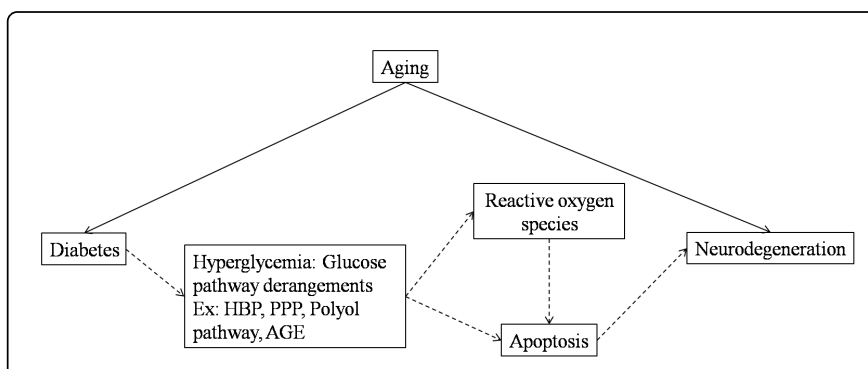

Figure 1: Schematic representation of possible mechanisms of Diabetes/Hyperglycemia-mediated ROS and Apoptosis as a cause of Neurodegeneration. HBP - Hexosamine Biosynthetic Pathway, PPP - Pentose Phosphate Pathway, AGE - Advanced Glycation End products

\section{Hyperglycemia-mediated Apoptosis}

In general, an alteration in substrate energy metabolism under hyperglycemic conditions is a contributing factor for the various metabolic perturbations. Several glucose utilizing pathways are known to be involved in this process. Hyperglycemia-mediated detrimental effects may be mediated by various pathways of glucose utilization including the pentose phosphate pathway, polyol pathway, PKC activation, AGEs and hexosamine biosynthetic pathway.

Hyperglycemia-mediated apoptosis has been well documented in several previous studies [50,51]. For example, human umbilical vein endothelial cells exposed to $30 \mathrm{mM}$ high glucose for 72 hours exhibited increased apoptosis [52]. Moreover, aortic endothelial cells exposed to 
$30 \mathrm{mM}$ high glucose culturing conditions displayed greater glucose oxidation, increased superoxide production [53] and DNA damage. PARP is subsequently activated [54] resulting in apoptosis.

The hexosamine biosynthetic pathway (HBP) is known to play a role in high glucose-mediated apoptosis [55]. O-GlcNAcylation of certain proteins can lead to increased apoptosis. For example, hyperglycemia-induced HBP flux leads to greater O-GlcNAcylation of p53 resulting in increased angiotensin synthesis and apoptosis [56]. Recent studies have shown that increased flux through HBP and subsequent O-GlcNAcylation of certain pro-apoptotic proteins such as $\mathrm{BAD}$ leads to increased BAD-BCl-2 dimerization leading to increased apoptosis $[57,58]$.

Protein kinase $\mathrm{C}$ activation is another stress signal in hyperglycemic cells. PKC controls target protein function via serine and threonine residue phosphorylation. Upstream signals that activate PKC such as diacylglycerol (DAG) are found in higher concentrations under hyperglycemic conditions [59]. As a result of PKC activation during hyperglycemia there are various intracellular effects such as increased ROS production which could possibly lead to apoptosis [60].

High glucose conditions in the system also affects polyol (sorbitol) pathway, whereby the key enzyme aldolase reductase uses up reducing equivalents $(\mathrm{NADPH})$ resulting in a decrease in reduced glutathione [61]. This in turn leads to intracellular oxidative stress and subsequent ROS-mediated effects [62]. Additionally polyol pathway has also been linked to diabetic peripheral neuropathy [63]. Pentose phosphate pathway which has not been directly implicated in pathogenesis of diabetes may also play a possible role in exacerbating the effects of diabetes. Activation of the pentose phosphate pathway under hyperglycemic conditions due to higher utilization of NADPH, results in a high NADH: NAD+ ratio that results in de novo synthesis of diacylglycerol [64]. This results in PKC activation as explained previously or accumulation of dihydroxyacetone and other glycolytic metabolites causing further damage.

With diabetes hyperglycemia also directly leads to ROS production, increased cellular stress and glucotoxicity. In an upstream effect of hyperglycemia, production of increased amounts of reactive oxygen species is also known to have detrimental effects on cellular function [65]. The proposed mechanisms of oxidative stress-mediated diabetic complications include activation of transcription factors, advanced glycation end products (AGE) and protein kinase C (PKC) [66] as discussed earlier in this review. Excessive free radical production is known to damage cellular proteins, membrane lipids and nucleic acids eventually causing cell death [67]. Moreover, hyperglycemia, as such, may also act as a stress signal, resulting in cytochrome-c release, the activation of caspase-3 [50] and apoptosis and apoptotic cell death in response to hyperglycemia may be dose-dependent indicating a greater degree of apoptosis at higher glucose levels [50]. Although there are a handful of mechanisms that can cause hyperglycemiamediated apoptosis, there is limited data on their effects on neuronal cells per se. Hence further studies focusing on the effect of each of the above mentioned glucose pathways on neurodegenaration are necessary.

\section{Could Aging be a Possible Link?}

It has been widely accepted that both diabetes and neurodegeneration are prevalent in aging/aged individuals. Aging exacerbates incidence of both diabetes and neurodegeneration and provides a possible common link between the two conditions.
Impaired glucose tolerance in aged individuals has been shown to be affected by various aspects of aging such as changes in lean body mass, altered insulin secretion, etc. [68]. Although age has pointed towards increased incidence of neurodegeneration in normal and diabetic individuals, whether diabetes poses increased risk of developing neurodegenerative disorders in aging/aged individuals needs more probing. The actual mechanisms involved are of great interest and a potential future direction for neurophysiological research.

The role of mitochondria cannot be over looked in the context of aging and metabolism. Mitochondrial free radical production, as mentioned earlier, might be linked to apoptosis, in addition to being a driving force in accelerated aging [69]. Hence a possible combination of mitochondrial oxidative damage triggering apoptosis and aging under hyperglycemic conditions is yet another link between diabetes, aging and neurodegeneration. Bechmann et al. observed that uncoupling proteins (UCP) 2 play a role in protecting against neuronal injury. They report that induction of UCP2 after lesions in mice result in a decreased activation of caspase 3 and thereby decreased apoptosis in brain [70]. Interestingly there have been studies that identify UCP2 as a glucose sensor regulating ATP production [71]. Methyl glyoxal (Advanced Glycation End product - AGE) may be a promoter of neuronal death via AGE formation [30]. AGE-cross-linked aggregates could also possibly contribute to pathophysiology of $\mathrm{AD}$.

AGEs are known to be neurotoxic [72,73] and increase the cytotoxicity of amyloid-beta fragments [74]. Given that hyperglycemia leads to AGE formation which in turn is linked to neurodegeneration, anti-AGE and anti-glycation drugs could be possible therapeutic targets.

\section{Therapeutic Targets}

Although there have been no known pharmacological treatments for diabetes-mediated neurodegeneration till date, this section would discuss possible therapeutic strategies in improving cognitive health in diabetics. Additionally, known adverse effects that need to be considered when administering treatments will also be discussed. Some studies have suggested that a tighter control of glucose levels might prove beneficial $[75,76]$ however this claim has not been confirmed as a few other groups showed no improvements in cognitive decline [77]. In fact tight glycemic control could possibly cause hypoglycemia which is causal agent for cognitive decline $[78,79]$. Some studies have shown a beneficial effect of oral anti-diabetic drugs on cognition e.g. thiazolidinediones [80] however other larger trials on similar drugs such as rosiglitazone did not show any beneficial effect [81]. On the other hand metformin has been shown to accelerate symptoms of $\mathrm{AD}$ in diabetic patients due to increases in amyloid peptides [82] and also accelerate cognitive decline in T2DM [83]. Effect of other glucose-lowering drugs such as sulfonylureas could possibly be tested for effects on cognitive performance.

Anti-glycation agents could be another angle for tackling high glucose mediated cognitive decline. Carnosine, a naturally occurring dipeptide in human tissues is an anti-glycation agent which reduces AGE formation by reacting with aldehydes and ketones [84]. Carnosine supplementation as well as carnosinase inhibitors could prove helpful in treating AGE-mediated diabetic neurodegeneration. Similarly inhibitors of AGE-induced cross-links as well as cross-link breakers such as amidoguanidine [85] and thiazolium salts respectively could also be tested for efficacy in treating diabetes-mediated AGElinked neurodegeneration [86]. 
Pleiotropic drugs with several beneficial effects have gained popularity recently and are being widely tested recently. Since there are several possible causes for diabetes-mediated neurodegeneration, drugs with pleiotropic effects could be very effective in treating several adverse effects. Example: Actovegin, a drug known for its effects such as improved glucose utilization, increased neuron survival, reduction in oxidative stress, inhibition of PARP and reduced apoptosis has also been studied to have neuroprotective and metabolic effects [87]. Hence it would be worth testing Activegin and similar pleiotropic drugs for possible neuroprotective effects alongside several other positive pleiotropic effects.

Several anti-oxidants have also shown beneficial neurological effects. Ascorbic acid for instance is helpful in memory restoration in aged mice [88]. Vitamin E, also a known antioxidant, is reported to reduce the risk of $\mathrm{AD}[89,90]$. Alpha-hydroxy cinnamic acid has also been shown to reduce hyperglycemia-mediated apoptosis [57]. Additionally, oleanolic acid also decreases high glucose-mediated apoptosis [91]. The advantage of using nutraceuticals in bringing about anti-apoptotic effects may prove crucial in focusing therapeutic efforts on minimal side effect natural food-based drugs e.g resveratrol from red grapes, quercetin [92], cinnamic acid from cinnamon and oleanolic acid from cloves. The effect of these antioxidants in improving neurological function is worth studying in future. As an upstream cause for apoptosis, oxidative stress has been shown to mediate several molecular damages as explained previously. It activates transcription factors, advanced glycation end products (AGE) and protein kinase $\mathrm{C}(\mathrm{PKC})$ and is known to damage cellular proteins, membrane lipids and nucleic acids eventually causing cell death. Antioxidant treatment can prove helpful in reversing these effects, decreasing cell death and hence improving cognitive function.

As mentioned above, there are not any identified treatments for dementia or neurodegeneration. Exploring available drugs used in treatment of diabetes, anti-glycation drugs or antioxidants and testing their efficiency in cognitive improvement will possibly prove beneficial in employing novel treatments for neurodegeneration. The scope of studying various therapeutic targets in neurodegeneration is wide. Since not much work has been done so far to identify an effective treatment for improving cognitive function, the above mentioned possibilities should be explored in future.

In conclusion, neurodegeneration has been shown to be exacerbated by diabetes and hyperglycemia. Hyperglycemia-mediated apoptosis, oxidative stress, AGE, PKC activation, etc. could be possible mechanisms of neurodegeneration in diabetics. Therapeutic targets aimed at attenuating the above mentioned mechanisms could possibly ameliorate neurodegeneration in diabetic patient. Further research on the various mechanisms and therapeutic targets is required to get answers to this very compelling problem.

\section{References}

1. Danaei G (2011) National, regional, and global trends in fasting plasma glucose and diabetes prevalence since 1980: systematic analysis of health examination surveys and epidemiological studies with 370 country-years and 2.7 million participants. Lancet, 378: 31-40.

2. Whiting DR, Guariguata L, Weil C, Shaw J (2011) IDF diabetes atlas: global estimates of the prevalence of diabetes for 2011 and 2030. Diabetes Res Clin Pract 94: 311-321.

3. International Diabetes Federation.

4. HE Resnick, Harris MI, Brock DB, Harris TB (2000) American Diabetes Association diabetes diagnostic criteria, advancing age, and cardiovascular disease risk profiles: results from the Third National Health and Nutrition Examination Survey. Diabetes Care 23: 176-180.

5. Whitmer RA (2007) Type 2 diabetes and risk of cognitive impairment and dementia. Curr Neurol Neurosci Rep 7: 373-380.

6. McKusick VA (2007) Mendelian Inheritance in Man and its online version, OMIM. Am J Hum Genet 80: 588-604.

7. Coker LH, Shumaker SA (2003) Type 2 diabetes mellitus and cognition: an understudied issue in women's health. J Psychosom Res 54: 129-139.

8. Kalmijn S, Feskens EJ, Launer LJ, Stijnen T, Kromhout D (1995) Glucose intolerance, hyperinsulinaemia and cognitive function in a general population of elderly men. Diabetologia 38: 1096-1102.

9. Gregg E.W, Yaffe K, Cauley JA, Rolka DB, Blackwell TL, et al. (2000) Is diabetes associated with cognitive impairment and cognitive decline among older women? Study of Osteoporotic Fractures Research Group. Arch Intern Med 160: 174-80.

10. Leibson CL, Rocca WA, Hanson VA, Cha R, Kokmen E, et al. (1997) Risk of dementia among persons with diabetes mellitus: a population-based cohort study. Am J Epidemiol 145: 301-308.

11. Peila R, Rodriguez BL, Launer LJ (2002) Type 2 diabetes, APOE gene, and the risk for dementia and related pathologies: The Honolulu-Asia Aging Study. Diabetes 51: 1256-1262.

12. Luchsinger JA, Tang MX, Stern Y, Shea S, Mayeux R (2001) Diabetes mellitus and risk of Alzheimer's disease and dementia with stroke in a multiethnic cohort. Am J Epidemiol 154: 635-641.

13. Ott A, Stolk RP, van Harskamp F, Pols HA, Hofman A, et al. (1999) Diabetes mellitus and the risk of dementia: The Rotterdam Study. Neurology 53: 1937-1942.

14. Gold SM, Dziobek I, Sweat V, Tirsi A, Rogers K, et al. (2007) Hippocampal damage and memory impairments as possible early brain complications of type 2 diabetes. Diabetologia 50: 711-719.

15. Laffel L (1999) Ketone bodies: a review of physiology, pathophysiology and application of monitoring to diabetes. Diabetes Metab Res Rev 15: 412-426.

16. Kety SS, Schmidt CF (1948) THE nitrous oxide method for the quantitative determination of cerebral blood flow in man: theory, procedure and normal values. J Clin Invest 27: 476-483.

17. Sokoloff L (1989) Circulation and energy metabolism of the brain. In: Siegel G, Agranoff B, Albers RW, and Molinoff P, eds. Basic neurochemistry: molecular, cellular, and medical aspects, 4th ed. New York: Raven Press.

18. Edvinsson L, McCulloch J (1993) Cerebral blood flow and metabolism. New York: Raven Press.

19. Owen OE, Morgan AP, Kemp HG, Sullivan JM, Herrera MG, et al. (1967) Brain metabolism during fasting. J Clin Invest 46: 1589-1595.

20. Hawkins BT, Lundeen TF, Norwood KM, Brooks HL, Egleton RD et al. (2007) Increased blood-brain barrier permeability and altered tight junctions in experimental diabetes in the rat: contribution of hyperglycaemia and matrix metalloproteinases. Diabetologia 50: 202-211.

21. Starr JM, Wardlaw J, Ferguson K, Mac Lullich, Dear IJ, et al. (2003) Increased blood-brain barrier permeability in type II diabetes demonstrated by gadolinium magnetic resonance imaging. J Neurol Neurosurg Psychiatry 74:707-706.

22. Gandhi GK, Ball KK, Cruz NF, Dienel GA (2010) Hyperglycaemia and diabetes impair gap junctional communication among astrocytes. ASN Neuro 2: e00030.

23. Seaquist ER, Damberg GS, Tkac I, Gruetter R (2001) The effect of insulin on in vivo cerebral glucose concentrations and rates of glucose transport/ metabolism in humans. Diabetes 50: 2203-2209.

24. van Elderen SG, de Roos A, de Craen AJ, Westendorp RG, Blauw GJ, et al. (2010) Progression of brain atrophy and cognitive decline in diabetes mellitus: a 3-year follow-up. Neurology 75: 997-1002.

25. de Bresser J, Tiehuis AM, van den Berg E, Reijmer YD, Jongen C, et al. (2010) Progression of cerebral atrophy and white matter hyperintensities in patients with type 2 diabetes. Diabetes Care 33: 1309-1314. 
26. Yi SS, Hwang IK, Kim DW, Shin JH, Nam SM, et al. (2011) The chronological characteristics of SOD1 activity and inflammatory response in the hippocampi of STZ-induced type 1 diabetic rats. Neurochem Res 36: 117-128.

27. Revill P, Moral MA, Prous JR (2006) Impaired insulin signaling and the pathogenesis of Alzheimer's disease. Drugs Today (Barc) 42: 785-790.

28. Mosconi L (2005) Brain glucose metabolism in the early and specific diagnosis of Alzheimer's disease. FDG-PET studies in MCI and AD. Eur J Nucl Med Mol Imaging 32: 486-510.

29. Brownlee M (1995) Advanced protein glycosylation in diabetes and aging. Annu Rev Med 46: 223-234.

30. Guo Q, Mori T, Jiang Y, Hu C, Osaki Y, et al. (2009) Methylglyoxal contributes to the development of insulin resistance and salt sensitivity in Sprague-Dawley rats. J Hypertens 27: 1664-1671.

31. Dias WB, Hart GW (2007) O-GlcNAc modification in diabetes and Alzheimer's disease. Mol Biosyst 3: 766-772.

32. Ke YD, Delerue F, Gladbach A, Götz J, Ittner LM (2009) Experimental diabetes mellitus exacerbates tau pathology in a transgenic mouse model of Alzheimer's disease. PLoS One 4: e7917.

33. Heitner J, Dickson D (1997) Diabetics do not have increased Alzheimertype pathology compared with age-matched control subjects. A retrospective postmortem immunocytochemical and histofluorescent study. Neurology 49: 1306-1311.

34. Schmidt R, Launer LJ, Nilsson LG, Pajak A, Sans S, et al. (2004) Magnetic resonance imaging of the brain in diabetes: the Cardiovascular Determinants of Dementia (CASCADE) Study. Diabetes 53: 687-692.

35. Kamada H, Yu F, Nito C, Chan PH (2007) Influence of hyperglycemia on oxidative stress and matrix metalloproteinase-9 activation after focal cerebral ischemia/reperfusion in rats: relation to blood-brain barrier dysfunction. Stroke 38: 1044-1049.

36. Launer LJ (2009) Diabetes: vascular or neurodegenerative: an epidemiologic perspective. Stroke 40: S53-55.

37. Eschwege E, Richard JL, Thibult N, Ducimetière P, Warnet JM, et al. (1985) Coronary heart disease mortality in relation with diabetes, blood glucose and plasma insulin levels. The Paris Prospective Study, ten years later. Horm Metab Res Suppl 15: 41-46.

38. Pannacciulli N, De Pergola G, Ciccone M, Rizzon P, Giorgino F, et al. (2003) Effect of family history of type 2 diabetes on the intima-media thickness of the common carotid artery in normal-weight, overweight, and obese glucose-tolerant young adults. Diabetes Care 26: 1230-1234.

39. Ciccone M, Pietro Scicchitano, Matteo Cameli, Annagrazia Cecere, Francesca Cortese, et al. (2014) Endothelial function in Pre-Diabetes, Diabetes and Diabetic Cardiomyopathy: A Review. J Diab Metab :4.

40. Haan MN, Shemanski L, Jagust WJ, Manolio TA, Kuller L (1999) The role of APOE epsilon4 in modulating effects of other risk factors for cognitive decline in elderly persons. JAMA 282: 40-46.

41. Kalmijn S, Feskens EJ, Launer LJ, Kromhout D (1996) Cerebrovascular disease, the apolipoprotein e4 allele, and cognitive decline in a community-based study of elderly men. Stroke 27: 2230-2235.

42. Irie F, Fitzpatrick AL, Lopez OL, Kuller LH, Peila R, et al. (2008) Enhanced risk for Alzheimer disease in persons with type 2 diabetes and APOE epsilon4: the Cardiovascular Health Study Cognition Study. Arch Neurol 65: 89-93.

43. Thomas LB1, Gates DJ, Richfield EK, O'Brien TF, Schweitzer JB, et al. (1995) DNA end labeling (TUNEL) in Huntington's disease and other neuropathological conditions. Exp Neurol 133: 265-272.

44. Troost D, Aten J, Morsink F, de Jong JM (1995) Apoptosis in amyotrophic lateral sclerosis is not restricted to motor neurons. Bcl-2 expression is increased in unaffected post-central gyrus. Neuropathol Appl Neurobiol 21: 498-504.

45. Smale G, Nichols NR, Brady DR, Finch CE, Horton WE Jr (1995) Evidence for apoptotic cell death in Alzheimer's disease. Exp Neurol 133: 225-230.

46. Gervais FG, Xu D, Robertson GS, Vaillancourt JP, Zhu Y, et al. (1999) Involvement of caspases in proteolytic cleavage of Alzheimer's amyloid- beta precursor protein and amyloidogenic A beta peptide formation. Cell 97: 395-406.

47. Garden GA, Budd SL, Tsai E, Hanson L, Kaul M, et al. (2002) Caspase cascades in human immunodeficiency virus-associated neurodegeneration. J Neurosci 22: 4015-4024.

48. Klevenyi P, Andreassen O, Ferrante RJ, Schleicher JR Jr, Friedlander RM, et al. (1999) Transgenic mice expressing a dominant negative mutant interleukin-1beta converting enzyme show resistance to MPTP neurotoxicity. Neuroreport 10: 635-638.

49. Kim B, Backus C, Oh S, Hayes JM, Feldman EL (2009) Increased tau phosphorylation and cleavage in mouse models of type 1 and type 2 diabetes. Endocrinology 150: 5294-5301.

50. Cai L, Li W, Wang G, Guo L, Jiayng Y, et al. (2002) Hyperglycemiainduced apoptosis in mouse myocardium: mitochondrial cytochrome Cmediated caspase-3 activation pathway. Diabetes 51:1938-1948.

51. Moley KH, Chi MM, Knudson CM, Korsmeyer SJ, Mueckler MM (1998) Hyperglycemia induces apoptosis in pre-implantation embryos through cell death effector pathways. Nat Med 4: 1421-1424.

52. Ido Y, Carling D, Ruderman N (2002) Hyperglycemia-induced apoptosis in human umbilical vein endothelial cells: inhibition by the AMPactivated protein kinase activation. Diabetes 51: 159-167.

53. Nishikawa T, Edelstein D, Du XL, Yamagishi S, Matsumura T, et al. (2000) Normalizing mitochondrial superoxide production blocks three pathways of hyperglycaemic damage. Nature 404: 787-790.

54. Du X, Matsumura T, Edelstein D, Rossetti L, Zsengellér Z, et al. (2003) Inhibition of GAPDH activity by poly(ADP-ribose) polymerase activates three major pathways of hyperglycemic damage in endothelial cells. J Clin Invest 112: 1049-1057.

55. Fülöp N, Marchase RB, Chatham JC (2007) Role of protein O-linked Nacetyl-glucosamine in mediating cell function and survival in the cardiovascular system. Cardiovasc Res 73: 288-297.

56. Fiordaliso F, Leri A, Cesselli D, Limana F, Safai B, et al. (2001) Hyperglycemia activates p53 and p53-regulated genes leading to myocyte cell death. Diabetes 50: 2363-2375.

57. Rajamani U, M.F. Essop (2010) Hyperglycemia-mediated activation of the hexosamine biosynthetic pathway results in myocardial apoptosis. Am J Physiol Cell Physiol 299: 139-147.

58. Rajamani U, Joseph D, Roux S, Essop MF (2011) The hexosamine biosynthetic pathway can mediate myocardial apoptosis in a rat model of diet-induced insulin resistance. Acta Physiol (Oxf) 202: 151-157.

59. Koya D, Jirousek MR, Lin YW, Ishii H, Kuboki K, et al. (1997) Characterization of protein kinase $\mathrm{C}$ beta isoform activation on the gene expression of transforming growth factor-beta, extracellular matrix components, and prostanoids in the glomeruli of diabetic rats. J Clin Invest 100: 115-126.

60. Xia P, Inoguchi T, Kern TS, Engerman RL, Oates PJ, et al. (1994) Characterization of the mechanism for the chronic activation of diacylglycerol-protein kinase $\mathrm{C}$ pathway in diabetes and hypergalactosemia. Diabetes 43: 1122-1129.

61. Lee AY, Chung SS (1999) Contributions of polyol pathway to oxidative stress in diabetic cataract. FASEB J 13: 23-30.

62. Brownlee M (2005) The pathobiology of diabetic complications: a unifying mechanism. Diabetes 54: 1615-1625.

63. Oates PJ (2002) Polyol pathway and diabetic peripheral neuropathy. Int Rev Neurobiol 50: 325-392.

64. Larkins RG, Dunlop ME (1992) The link between hyperglycaemia and diabetic nephropathy. Diabetologia 35: 499-504.

65. Finkel T, Holbrook NJ (2000) Oxidants, oxidative stress and the biology of ageing. Nature 408: 239-247.

66. Baynes JW, Thorpe SR (1999) Role of oxidative stress in diabetic complications: a new perspective on an old paradigm. Diabetes 48: 1-9.

67. Jiang Z Y, Woollard A C, Wolff S P (1990) Hydrogen peroxide production during experimental protein glycation. FEBS Lett 268: 69-71.

68. Horwitz DL (1982)Diabetes and aging. The American Journal of Clinical Nutrition 36: 803-808. 
Citation: Rajamani U (2014) Causes of Neurodegeneration in Diabetes: Possible Culprits and Therapeutic Targets. Brain Disord Ther 3: 130. doi:10.4172/2168-975X.1000130

Page 6 of 6

69. Sanz A, Stefanatos RK (2008) The mitochondrial free radical theory of aging: a critical view. Curr Aging Sci 1: 10-21.

70. Bechmann I, Diano S, Warden CH, Bartfai T, Nitsch R, et al. (2002) Brain mitochondrial uncoupling protein 2 (UCP2): a protective stress signal in neuronal injury. Biochem Pharmacol 64: 363-367.

71. Joseph JW, Koshkin V, Zhang CY, Wang J, Lowell BB, et al. (2002) Uncoupling protein 2 knockout mice have enhanced insulin secretory capacity after a high-fat diet. Diabetes 51:3211-3219.

72. Yan SD, Chen X, Schmidt AM, Brett J, Godman G, et al. (1994) Glycated tau protein in Alzheimer disease: a mechanism for induction of oxidant stress. Proc Natl Acad Sci U S A 91: 7787-7791.

73. Takeuchi M, Bucala R, Suzuki T, Ohkubo T, Yamazaki M, et al. (2000) Neurotoxicity of advanced glycation end-products for cultured cortical neurons. J Neuropathol Exp Neurol 59: 1094-1105.

74. Woltjer RL, Maezawa I, Ou JJ, Montine KS, Montine TJ (2003) Advanced glycation endproduct precursor alters intracellular amyloid-beta/A beta PP carboxy-terminal fragment aggregation and cytotoxicity. J Alzheimers Dis 5: 467-476.

75. Ryan CM, Freed MI, Rood JA, Cobitz AR, Waterhouse BR, et al. (2006) Improving metabolic control leads to better working memory in adults with type 2 diabetes. Diabetes Care 29: 345-351.

76. Luchsinger JA, Palmas W, Teresi JA, Silver S, Kong J, et al. (2011) Improved diabetes control in the elderly delays global cognitive decline. J Nutr Health Aging 15: 445-449.

77. Diabetes Control and Complications Trial/Epidemiology of Diabetes Interventions and Complications Study Research Group, Jacobson AM, Musen G, Ryan CM, Silvers N, et al. (2007) Long-term effect of diabetes and its treatment on cognitive function. N Engl J Med 356: 1842-1852.

78. Whitmer RA, Karter AJ, Yaffe K, Quesenberry CP Jr, Selby JV (2009) Hypoglycemic episodes and risk of dementia in older patients with type 2 diabetes mellitus. JAMA 301: 1565-1572.

79. Warren RE, Frier BM (2005) Hypoglycaemia and cognitive function Diabetes Obes Metab 7: 493-503.

80. Risner ME, Saunders AM, Altman JF, Ormandy GC, Craft S, et al. (2006) Efficacy of rosiglitazone in a genetically defined population with mild-tomoderate Alzheimer's disease. Pharmacogenomics J 6: 246-254.

81. Harrington C, Sawchak S, Chiang C, Davies J, Donovan C, et al. (2011) Rosiglitazone does not improve cognition or global function when used as adjunctive therapy to AChE inhibitors in mild-to-moderate Alzheimer's disease: two phase 3 studies. Curr Alzheimer Res 8: 592-606.

82. Chen Y, Zhou K, Wang R, Liu Y, Kwak YD, et al. (2009) Antidiabetic drug metformin (GlucophageR) increases biogenesis of Alzheimer's amyloid peptides via up-regulating BACE1 transcription. Proc Natl Acad Sci U S A 106: 3907-3912.

83. Moore EM, Mander AG, Ames D, Kotowicz MA, Carne RP, et al. (2013) Increased risk of cognitive impairment in patients with diabetes is associated with metformin. Diabetes Care 36: 2981-2987.

84. Münch G, Kuhla B, Lüth HJ, Arendt T, Robinson SR (2003) AntiAGEing defences against Alzheimer's disease. Biochem Soc Trans 31: 1397-1399.

85. Kern TS, Engerman RL (2001) Pharmacological inhibition of diabetic retinopathy: aminoguanidine and aspirin. Diabetes 50: 1636-1642.

86. Vasan S, Foiles PG, Founds HW (2001) Therapeutic potential of AGE inhibitors and breakers of AGE protein cross-links. Expert Opin Investig Drugs 10: 1977-1987.

87. Machicao F, Muresanu DF, Hundsberger H, Pflüger M, Guekht A (2012) Pleiotropic neuroprotective and metabolic effects of Actovegin's mode of action. J Neurol Sci 322: 222-227.

88. Parle M, Dhingra D (2003) Ascorbic Acid: a promising memoryenhancer in mice. J Pharmacol Sci 93: 129-135.

89. Guerrero AL, Dorado-Martínez C, Rodriguez A, Pedroza-Ríos K, Borgonio-Pérez G, et al. (1999) Effects of vitamin E on ozone-induced memory deficits and lipid peroxidation in rats. Neuroreport 10: 1689-1692.

90. Morris MC, Evans DA, Bienias JL, Tangney CC, Bennett DA, et al. (2002) Dietary intake of antioxidant nutrients and the risk of incident Alzheimer disease in a biracial community study. JAMA 287: 3230-3237.

91. Mapanga RF, Rajamani U, Dlamini N, Zungu-Edmondson M, KellyLaubscher R, et al. (2012) Oleanolic acid: a novel cardioprotective agent that blunts hyperglycemia-induced contractile dysfunction. PLoS One 7: e47322.

92. Scicchitano F (2014) Nutraceuticals and dyslipidaemia: Beyond the common therapeutics. J Func Foods 11-32. 